\title{
TEORIA DA CONVENIÊNCIA FUNCIONAL: UMA REFLEXÃO SOBRE AS PROPRIEDADES FUNDAMENTAIS DA MATÉRIA
}

\section{ENSAIO TEÓRICO}

JÚNIOR, Jayme Marrone ${ }^{1}$

JÚNIOR, Jayme Marrone. Teoria da Conveniência Funcional: Uma reflexão sobre as propriedades fundamentais da matéria. Revista Científica Multidisciplinar Núcleo do Conhecimento. Ano 04, Ed. 07, Vol. 12, pp. 133-157. Julho de 2019. ISSN: 24480959

\section{RESUMO}

Este ensaio tem como objetivo principal provocar uma reflexão sobre a possibilidade de considerar a análise da forma, no contexto do Modelo Padrão da Física de Partículas, como um dos critérios de descrição das forças fundamentais. Utilizando os conceitos de massa e carga elétrica, pretendo mostrar que a manifestação destas qualidades é resultado de um processo de auto-organização dos sistemas e não uma característica inerente à partícula. Por meio de uma pesquisa bibliográfica nas bases das ciências naturais e humanas, sobre as propriedades da matéria bem como sua relevância na definição do que entendemos por realidade, construo um esboço intuitivo de uma teoria que coloca a existência das coisas sob a dependência de sua funcionalidade e a materialidade do mundo entrelaçada nas relações entre observador e observado. A teoria, ainda em desenvolvimento, além de permitir outra compreensão sobre as propriedades físicas das particulas também se desdobra sobre as relações sistêmicas em outros níveis, incluindo o social. Entendo que o princípio auto-organizativo que desencadeia a manifestação de propriedades físicas convenientemente funcionais em sistemas de partículas subatômicas, regendo o comportamento das mesmas, também se aplica no desenvolvimento das relações entre sujeitos cognoscentes quando estes constroem sua própria interpretação da realidade. Ainda é possível estender a teoria como uma alternativa de interpretação

\footnotetext{
${ }^{1}$ Doutorando em Ensino de Ciências, Mestre em Ensino de ciências e educação matemática, Especialista em Neurociências, Especialista em Recursos Humanos, Graduado em Física e em Engenharia Mecânica. 
da hipótese da causação formativa e da existência de campos morfogenéticos. Propomos então fomentar uma discussão em âmbito interdisciplinar cujo intuito é visualizar uma compreensão de mundo em termos menos complexos onde a importância de uma associação supera as necessidades individuais de seus integrantes.

Palavras-chave: Forma, auto-organização, funcionalidade.

\section{INTRODUÇÃO}

Nos últimos anos a abordagem neurocientífica se tornou uma referência em pesquisas que buscam entender o ser humano em níveis que vão do fisiológico ao social. O caminho para se conseguir uma explicação razoável acerca do funcionamento e da capacidade do cérebro, bem como sua influência em nosso comportamento exige uma composição de conteúdos que transcendem a especificidade de cada área do saber e mobilizam uma gama de cientistas que trabalham e pesquisam de forma multirreferencial.

Diante deste cenário acredito que a Física possa contribuir com algumas discussões principalmente com os conceitos da física moderna, mais especificamente da mecânica quântica. Assumindo minha limitação na compreensão efetiva sobre a Física Quântica e ainda assim com intenção de favorecer a discussão, configuro uma teoria que talvez possa acomodar algumas questões, dentre elas uma das que mais incomoda a comunidade científica que é a percepção da realidade.

Os elementos fisiológicos que captam a realidade e formam nossos sentidos (visão, audição, tato, olfato, paladar) são manipulados e interpretados por uma extensa e complexa rede neural. O caminho desta percepção inicia quando o estímulo é detectado por um neurônio sensitivo que converte (luz, som, cheiro, toque) em potenciais de ação que desencadeiam um sinal de origem eletroquímica. O sinal é conduzido a uma área de processamento primário de acordo com a natureza do estímulo que por sua vez elabora as características iniciais da informação tal como forma, textura, cor, etc. A partir daí a informação elaborada por comparação é transmitida aos centros de processamento secundário da região talâmica onde se incorpora à outras informações de origem límbica relacionadas com experiências 
passadas (memórias). Por fim chega ao seu centro cortical específico (visual, olfativo, etc.) já deveras alterado.

É possível observar, que mesmo neste breve e simplificado resumo do caminho percorrido pelo estímulo, a enorme quantidade de variáveis que podem afetar a percepção da realidade e ainda, a dependência que a mesma possui de uma lembrança análoga para que a informação possa ser classificada e compreendida cognitivamente. Desta maneira é razoável afirmar que cores, sabores, cheiros, texturas existem apenas em nossa mente de acordo com os modelos que construímos de nossas experiências do mundo. Mesmo sensações de objetos inexistentes podem ser experimentados dependendo da área cortical estimulada. Uma experiência realizada com uma jovem epilética de 22 anos pela equipe de Olaf Blanke da Escola Politécnica Federal de Lausanne na Suíça, mostrou que ao aplicar estimulação elétrica localizada perto da região de origem dos ataques epilépticos (junção temporoparietal esquerda), a paciente revelou sentir que "alguém" estava postado exatamente atrás dela.

Experiências deste tipo revelam que as percepções por vezes diferem qualitativamente do estímulo físico pois o cérebro é sensibilizado pelos dados e os interpreta baseado em experiências anteriores que servem de suporte cognitivo para acomodá-los e consequentemente atribuir algum significado em sua associação.

A informação que não se adequa ao modelo construído ou que não pode ser apropriada com o arcabouço de memórias prévias, é interpretada como uma perturbação exigindo sua dispensa e consequente não percepção ou sua incorporação por meio de uma remodelação das estruturas sinápticas reorganizando os circuitos neurais de acordo com a conveniência na necessidade de sua percepção.

Essa conveniência é ratificada por exemplo quando acreditamos na continuidade dos objetos que percebemos em nosso redor. Na verdade, as imagens formadas em nossa retina persistem no local em torno de $0,1 \mathrm{~s}$ até que se possa receber outro estímulo visual, ou seja, ficamos cegos durante esse tempo. Se pensarmos que o olho, na tentativa de captar o ambiente, movimenta de um ponto a outro em saltos e que isso ocorre em torno de 150 mil vezes diariamente, temos basicamente de 3 a 4 horas de cegueira por dia. 
A sensação da fragmentação das imagens seria como se olhássemos para alguém e não víssemos uma parte de sua cabeça, o que levaria todo o sistema a um colapso de energia para tentar entender como uma pessoa sem aquela parte poderia estar ali na sua frente conversando tranquilamente. Para evitar isso, é conveniente ao organismo que o cérebro complete a parte que falta com a memória da mesma ou similar, que em outra situação, ele já tenha experienciado. É necessária uma modulação das estruturas que compõem a percepção da realidade para que o sistema continue funcional.

Este trabalho envolve uma alternativa de compreensão das causas que promovem essa reorganização ao nível sináptico, articulando as propriedades físicas da matéria com a dinâmica destas redes neurais.

É com esse intuito que descreverei brevemente as discussões que pautaram o desenvolvimento desta teoria chamada a priori de Teoria da Conveniencia Funcional (TCF), cujo objetivo é acrescentar elementos que permitam uma descrição da realidade vinculada à materialidade dos objetos físicos ${ }^{[2]}$.

A percepção desta materialidade é uma experiência da consciência e racionalmente explicada em termos de partículas subatômicas tais como prótons, nêutrons e elétrons.

Tais partículas são definidas a partir de propriedades físicas como massa e carga elétrica, que diante do paradigma atual são consideradas inerentes à matéria e assim sendo toda realidade construída independe de quem observa, o que leva o senso comum a concluir que um prédio existe independente de uma mente consciente que o observa ou não.

Esse é o ponto a ser discutido já que entendo a materialidade como consequência da conveniência funcional de uma rede ou sistema. O vínculo entre observador e observado é funcional a ambos pois permite a manifestação da materialidade dos dois e de todo o sistema. Vivemos e experimentamos a realidade apenas em rede, ou seja, em conexão. 
Ressalto que massa, carga elétrica, cor e sabor, definidas pela física moderna como propriedades fundamentais da matéria e compreendidas pelo paradigma atual como intrínsecas ${ }^{[3]}$ às partículas verdadeiramente não o são.

Na revisão bibliográfica encontrei mais de sete definições e classificações do conceito massa. Os mais comuns estão associados ainda as concepções de Isaac Newton que incorpora a dificuldade de modificar o estado de repouso ou movimento de um objeto com sua massa, a chamada Inércia dos corpos. Foi possível ainda encontrar uma associação com um gradiente de energia, mas mesmo na Teoria da Relatividade Geral não há uma definição específica de massa.

Até Einstein teve certa dificuldade de compreender na totalidade o conceito em si, motivo este que o deixa sujeito a críticas sobre a dependência entre a mesma e a velocidade do corpo na Teoria da Relatividade Restrita. Ao que parece não há uma definição única do conceito, mesmo porque o mesmo encontra-se relativisticamente atrelado ao movimento, cuja compreensão também depende de um referencial.

Quando procurei uma definição de carga elétrica encontrei os mesmos obstáculos, ou seja, a comunidade cientifica parece direcionar o entendimento de carga elétrica a uma propriedade fundamental da partícula, ou uma qualidade da partícula, observada experimentalmente pelos desvios em suas trajetórias quando em movimento no interior de um campo magnético.

Segundo Hugh Young, et al. (2004), não é possível especificar exatamente o que é a carga elétrica, mas é possível descrever seu comportamento e suas propriedades. Os autores afirmam ainda, que a carga elétrica é uma das principais propriedades das partículas que constituem a matéria, tal como a massa. Sobre isto, Nussenzveig (2001) afirma que a carga elétrica é uma propriedade intrínseca de partículas que constituem a matéria.

O mundo físico, como conhecemos, está baseado nessas duas propriedades ditas fundamentais e atribuímos a noção de realidade à manifestação delas, ou seja, é real aquilo que é sensível aos nossos sentidos e que de alguma maneira interage conosco(introspecção). 
A evolução da Física segue no sentido de uma unificação destas interações fundamentais ${ }^{[4]}$, o que explicaria o Universo sob uma perspectiva muito mais simples. No entanto, na busca por um bloco fundamental percebemos que quanto mais tentamos isolá-los, mais elementos aparecem, por exemplo, olhamos para uma molécula e percebemos átomos, olhando para o átomo percebemos elétrons e núcleo, olhando para o núcleo percebemos prótons e nêutrons, olhando para estes percebemos os quarks e assim parece ser infinita a busca do bloco fundamental.

Cada vez que aprimorarmos nossas lentes sobre o mundo encontraremos mais elementos, não porque eles existem de maneira intrínseca à matéria, mas porque convenientemente atribuímos a eles uma função, um significado, justificando a nossa própria percepção dos mesmos.

Foi Albert Einstein quem inicialmente questionou o caráter inerentemente incerto da natureza em sua crítica ao indeterminismo de Niels Bohr. Segundo Einstein, a explicação para não encontramos o bloco fundamental da matéria não é porque a natureza é probabilística, mas porque não criamos ainda um instrumento adequado para medi-la.

O mundo quântico coloca algumas questões fundamentais diante do paradigma mecanicista de Newton, dentre elas duas me chama atenção: $O$ fato de que 0 ato de observar influencia o fenômeno e a outra, chamada de princípio da incerteza de Heisenberg diz que jamais saberemos com exatidão a posição e o movimento de partículas. Consequentemente o mundo é apenas uma aproximação da realidade e Born atribuía este fato a uma propriedade inerente à natureza.

Einstein não pôde aceitar isso, para ele uma descrição probabilística da natureza não podia ser a palavra final. A natureza era ordenada. Acreditava que, em nível mais profundo, tudo voltaria ao determinismo que conhecemos. Já para Niels Bohr, o sucesso da mecânica quântica falava por si só e ele via a relação entre observador e observado como uma expressão da nossa conexão com o mundo, mas em uma perspectiva de característica própria da natureza das coisas.

É esta discussão que inspira meu questionamento acerca do que é real. Penso que a realidade do Universo é consequência de sua funcionalidade, e a incerteza, bem como 
as propriedades fundamentais da matéria, são recursos necessários para convenientemente expandir os limites de suas funções. Desta maneira a expansão do Universo é a ampliação de seus atributos funcionais, justamente porque tentamos medi-lo, e ao fazê-lo oferecemos a ele mais uma função. Isso também se aplica a existência dos quarks e outras subpartículas.

Parece que se conseguimos interagir com as coisas e adjetivá-las como realidade é porque para nós sua existência é conveniente. A manifestação dessa realidade ocorre na conveniência do observador onde ele próprio é resultado desta conveniência em relação a um sistema mais complexo e assim indefinidamente.

Associo essa conveniência ao termo funcional pois percebemos a realidade naquilo que para nós é conveniente, aquilo que para nós tem alguma função de existir. Se isso não ocorrer, não percebemos, não é real.

Em sua teoria dos construtos pessoais, Kelly (1963) sugere que as pessoas desenvolvem sua noção de realidade conforme o seu entendimento sobre como o mundo funciona. Esses construtos são padrões, moldes, estruturas construídas para dar sentido ao que observam e experimentam.

Esta maneira de entender a realidade vai ao encontro de nossa perspectiva ao eleger a relação entre observador/observado como causadora da materialidade de ambos.

De certa forma, enquanto não for funcional para o sistema/rede tudo é uma questão de potencial(probabilidade) e a partir daí a concepção de onda de probabilidade faz sentido pois elimina a necessidade de atribuirmos inerência às coisas.

Reitero então que se de alguma forma um elemento for útil(funcional) as propriedades da matéria se manifestam se não, fica na forma de potencial criando, a partir do observador consciente, um campo de possibilidades.

Na questão dos estados de consciência, Damásio (2000) associa o fenômeno à percepção de si e do ambiente explicando assim que a materialidade de quem observa é por ele manifesta de acordo com o padrão neural que possui de si mesmo. Em outras palavras, criamos a realidade e somos por ela criados compondo um sistema/rede que não tem início nem fim no que diz respeito a materialização do que venha a ser RC: 34820

Disponível em: https://www.nucleodoconhecimento.com.br/fisica/conveniencia-funcional 
real. Podemos apenas descrever o estado do sistema em um dado ponto da linha temporal de seu desenvolvimento, ressaltando é claro o estado presente mas podendo sim transitar entre as memórias do passado e as projeções das previsões futuras, seguindo a linha de Kelly. Assim nos parece que a única medida capaz de estar associada a algum tipo de essência inerente ao homem em sua natureza é o Tempo, como veremos adiante.

Esta concepção de realidade pautada em uma relação entre observador/observado é verificada também a partir da Hipótese de Copenhagen ${ }^{[5]}$ que atribui ao ato de observar uma ação que provoca o colapso da função de onda. Significa que, embora antes da medição o estado do sistema permita muitas possibilidades, o processo de medição elege apenas uma delas aleatoriamente e a função de onda modifica-se para o resultado dessa escolha.

Considero nesta hipótese que não há aleatoriedade na escolha e sim uma funcionalidade pressuposta devido ao contexto em que a partícula se encontra. As relações necessárias à subsistência do sistema é que determina qual ou quais qualidades da partícula serão mais adequadas à manifestação.

No que diz respeito ao observador, ele só é parte integrante de um sistema se sua função integrativa contribuir para a subsistência do todo. É essa função integrativa, ou seja, a dependência entre os constituintes da rede que de forma hierárquica elege uma entre tantas possibilidades descritas na função de onda explicando desta forma porque indivíduos diferentes manifestam a mesma realidade. Caso um deles manifeste algo diferente, este evento não contribui para a formação do grupo. Aquele que não comunga da mesma manifestação se exclui.

A maior probabilidade no colapso da função de onda não é uma característica intrínseca ao ambiente ou especificamente do observador, mas uma necessidade do conjunto que os envolve, ao qual denominamos rede ou sistema.

A exemplo desse manuscrito, aceitamos sua existência independente de qualquer observador, no entanto a certeza de sua materialidade é construída a partir da necessidade de conexão entre autor e leitor ou entre quaisquer indivíduos que, por 
exemplo, o leem simultaneamente. Significa dizer que neste momento as palavras lidas existem porque possuem uma função ao leitor.

Na verdade, o exercício da função de escrever e da função de ler já é motivo para que este arranjo sistêmico exista e principalmente garante mais uma possibilidade de conexão. Entendo que compartilhar a materialidade do manuscrito com o outro cria um vínculo que pode eventualmente ser fortalecido e facilita a formação de um sistema com interesses comuns ou não, mas o que parece ser importante é o fato de que mesmo para se contraporem é necessária sua materialidade.

Participar de um grupo parece ser mais vantajoso, em termos de subsistência, do que permanecer isolado já que um conjunto, do ponto de vista organísmico, possui propriedades especificas, que isolados, seus integrantes não têm. Como contempladores da realidade que somos, fazemos isso a todo instante criando oportunidades sobrepostas a oportunidades e se acercando delas na tentativa de evitar o risco de não ter função, o que está atrelado a inexistência.

Desta maneira, se fosse possível imaginar uma partícula isolada de qualquer contexto, esta não manifestaria nem massa, nem carga elétrica, como o fóton. O que significa ser apenas um potencial, passível de transmissão tal como é a luz em seu caráter ondulatório.

Associar a realidade a uma organização sistêmica que atribui função ao que é observado(interação) constitui uma perspectiva mais simples sobre a compreensão do mundo e pode contribuir com a tentativa de unificação das interações fundamentais tendo como premissa o arranjo funcional dos estados auto-organizados (Forma) como propriedade fundamental que envolve todas as outras.

A proposta da Teoria é que os sistemas tendem a se auto organizarem para que sejam funcionais e a explicação para isso é a conveniência de sua própria existência. A ideia da reorganização dos circuitos neurais para construir nossa percepção da realidade tem na TCF um respaldo que reforça sua pertinência uma vez que o rearranjo sináptico é consequência da necessidade de aprimorar ou substituir funções neurais, fenômeno que remete à plasticidade cerebral, base da memória e da aprendizagem. 


\section{REFERENCIAIS TEÓRICOS}

Sobre a realidade do mundo o físico teórico italiano Carlo Rovelli (2017) sustenta minha expectativa acerca do mundo como construção mental. Em seu livro, "A realidade não é o que parece", ele discute alguns desdobramentos da mecânica quântica no sentido de que a mesma não descreve os objetos como são, mas como acontecem e como influenciam uns nos outros. O mundo real é o mundo das interações possíveis, onde a realidade é reduzida a relação.

A mecânica quântica, segundo Rovelli (2017), amplia essa relatividade dizendo que todas as características (para nós qualidades) de um objeto só existem em relação a outros objetos. Na proposta esta relação é a questão da funcionalidade entre os integrantes do sistema.

Para Rovelli o mundo descrito pela mecânica quântica contribui com a ideia de que a realidade não existe sem a relação entre sistemas físicos. Segundo o autor "Não são as coisas que podem entrar em relação, mas são as relações que dão origem à noção de coisa". (Rovelli 2017, p.113)

No que se refere à construção da realidade pelo indivíduo consciente recorro à Teoria dos Construtos Pessoais do Físico, Matemático e Psicólogo americano George Kelly já citado anteriormente. Embora Kelly sustente um universo alheio ao observador, a maneira como o ser se relaciona e constrói seu próprio universo a partir da sua conveniência é ponto chave deste trabalho. A conveniência está associada à necessidade de previsão e por consequência de controle, cujo intuito é a própria manutenção da existência. De acordo com Kelly, o universo existe por estar acontecendo e é nesse sentido que ele diz que o mesmo é real e integral, ou seja, todas as suas partes têm relação com cada uma das demais. O indivíduo participante do sistema e consciente dele, constrói sua própria interpretação do mundo a partir de suas experiências e as modula de acordo com sua conveniência na tentativa de prever e por isso ter função. A vida (a realidade), é pautada na proporção de sua utilidade(função) ao sistema e a morte é exato o oposto.

$\mathrm{Na}$ questão da consciência Chalmers (1995) coloca a informação como uma propriedade tão essencial da realidade quanto a matéria e a energia, sendo a 
experiência consciente uma característica fundamental, irredutível a qualquer coisa básica.

Entendo que a informação de Chalmers está relacionada a interação funcional, o que para Wheeler(1990) com seu conceito "the it from bit" aloca a informação de cada coisa, partícula, campo, força, mesmo o espaço-tempo, diante de seu próprio significado ( para nós sua função) derivado do que ele chama de "AparatoDesencadeador-de-Respostas. Para a TCF somente a mente consciente pode servir de "Aparato-Desencadeador-de-Respostas", mesmo porque nos parece que os questionamentos só são possíveis a partir de um estado especifico de consciência.

Diante do tema em questão não posso deixar de citar o físico indiano Amit Goswani[6] que em seu livro "O Universo Autoconsciente" afirma que é a consciência que cria a matéria, e não o oposto. Para ele, a consciência pode ser definida como: o agente que afeta objetos quânticos para Ihes tornar o comportamento passível de ser captado pelos sentidos, o que dá origem ao que denominamos realidade.

Para exemplificarmos, um elétron é considerado um objeto quântico já que seu comportamento por vezes é descrito como particula (ponto de matéria) e por outras como onda.

Para a Física Moderna não é possível afirmar que um objeto quântico se manifeste no espaço-tempo até que o observemos como uma partícula, e é neste ponto que Goswani afirma ser a consciência o fator responsável por produzir o colapso da função de onda, ou em outras palavras, é a consciência que provoca a materialização do observador e do objeto simultaneamente entrelaçados. Para a Teoria da Conveniência Funcional, o fenômeno da consciência surge da necessidade de quem a tenha de atribuir a si e/ou ao meio uma função que contribui com a existência e a manutenção da rede que os contém.

Para discutir a questão formação dos sistemas, não apenas do ponto de vista geométrico em sua estrutura física, mas também sob a perspectiva das organizações busco em Debrun (1996) os conceitos de Organização e Auto-organização (AO). Para o autor, uma organização, ou Forma é auto-organizada quando se produz a si própria.

Debrun distingue dois tipos de AO: 
a) AO Primária: ocorre quando um novo sistema se forma a partir do encontro de elementos que pertenciam a outros sistemas. Ex.: origem da vida.

b) AO Secundária: ocorre em um sistema já constituído, quando um novo padrão de organização se forma, a partir das interações entre seus componentes e com o ambiente. Ex.: jogo de basquete.

Sem aprofundarmos demais na teoria da auto-organização de Debrun, acredito que para este ensaio torna-se relevante a descrição dos elementos básicos que compõe a mesma:

1 - Da interação entre as partes se gera uma forma global nova no sistema.

2 - Durante o processo ocorrem adequações das e entre as partes.

3 - A Auto-organização nunca é absoluta; ela coexiste com a Hetero-Organização, que pode inclusive derivar do controle centralizado de um agente interno ao sistema.

4 - Os sistemas AO desenvolvem uma "hierarquia acavalada", em que os níveis “inferiores" não só são controlados pelos "superiores", mas também os controlam.

Dado que toda organização tem como base elementos discretos, convém apreciar que a forma auto-organizada não se produz no vazio, mas a partir de tais elementos. Considero as influências do meio externo como um dos fatores que desencadeiam o rearranjo sistêmico, mas este só ocorre mediante as relações entre os integrantes.

Em um processo de auto-organização não há nenhum tipo de controle imposto pelo meio na configuração do sistema, cujo único intuito é a subsistência do todo. O próprio sistema reconhece o meio e consequentemente cria a demanda de reestruturação. Isto ocorre porque é na necessidade de resolver as relações novas e antigas, entre os integrantes do sistema, que é pautada a existência do mesmo.

De certa maneira, se aplicarmos a TCF dentro do estudo das relações sociais, podemos dizer que criamos os problemas para resolvê-los não porque a solução é o objetivo, mas porque o que fazemos para solucioná-los nos atribui funcionalidade. Esta estratégia nos coloca em um status de importância dentro do universo criado. No 
fundo equivale dizer que estamos a todo momento mobilizando funções para nós mesmos cujo único objetivo é manter uma relação de dependência do sistema e viceversa.

O fenômeno da auto-organização também é discutido por Prigogine (1971) a partir da segunda lei da termodinâmica. $\mathrm{O}$ autor mostra que tal fenômeno gera estruturas dissipativas criadas e mantidas através de trocas de energia com o meio externo, em condições de não-equilíbrio. Estas estruturas dissipativas são dependentes de uma nova ordem, denominada por Prigogine como ordem por flutuações. Nestes processos auto-organizadores a estrutura é mantida por meio de dissipações energéticas, na qual a energia se desloca gerando simultaneamente a estrutura, através de um processo contínuo. Se as flutuações são pequenas, o sistema as acomoda, não modificando a sua estrutura organizacional, mas se as flutuações atingem um tamanho crítico, desencadeiam um desequilíbrio no sistema, ocasionando novas interações e reorganizações intra-sistêmicas. Os antigos modelos interagem entre eles de novas maneiras, e estabelecem novas conexões. As partes se reorganizam em um novo todo e o sistema alcança uma ordem mais elevada.

Note que Prigogine envolve o ambiente em uma necessidade de troca energética e não como controlador do processo auto-organizado. Para a TCF essa nova ordem sistêmica é que determina a materialidade funcional, e consequentemente, qual ou quais propriedades da partícula deverão se manifestar de acordo com sua conveniência.

\section{DESENVOLVIMENTO}

\subsection{A PROPOSTA}

Se a materialidade das coisas é atribuída pelo emaranhado composto pelo observador, observado e ambiente e ainda, que a necessidade de funcionalidade determina a manifestação das propriedades fundamentais, proponho que a realidade seja uma consequência da conveniência funcional deste sistema onde as relações é que são determinísticas e não os objetos. O próprio sistema cria e é criado a todo instante diante de uma única proposição, associar-se para existir. 
A busca de uma explicação mais simples do Universo direciona o pensamento físico a uma unificação das interações fundamentais. Não obstante essa necessidade ocorre porque anteriormente criamos tais interações para que separadamente pudéssemos dar conta uma descrição apropriada a cada contexto observado, ou seja, criamos a ideia de que estas interações existem por serem inerentes à natureza pois esquecemos que elas surgem quando tentamos delimitar um fenômeno. A tentativa de isolarmos determinado evento, para simplificar sua compreensão, tem como consequência o aparecimento de qualidades decorrentes da separação. Precisamos apenas entender que a atitude de delimitação é possível, mas sempre tendo em mente que algumas variáveis surgem não por serem intrínsecas ao objeto de estudo, mas resultado desta delimitação. É como se tentássemos separar um pedaço de uma rede de pesca. Imagine a rede sendo rompida e as pontas das conexões soltas. Elas são análogas as propriedades citadas, ou seja, só surgem porque tentamos delimitar uma parte do sistema. Se observarmos o pedaço fora do contexto (rede de pesca) podemos associar essas pontas soltas como intrínsecas ao pedaço, mas se entendermos o todo perceberemos que elas deixam de existir, pois seu movimento visa retomar as conexões, reorganizando a formação da rede íntegra novamente.

Não há motivo para descrevermos o universo em versões de massa, carga, cor ou sabor. Estas qualidades são suprimidas quando pensamos em uma associação. Significa dizer que não precisamos entender o que é massa para descrever a ação gravitacional, mas compreender qual a função da massa dentro do contexto, nem do caráter carga elétrica, mas da função carga e assim sucessivamente.

A natureza pode ser descrita por sua conveniente função sendo as propriedades fundamentais da matéria apenas traços (pontas soltas) decorrentes da criação de subsistemas (rupturas do todo) e cuja percepção, se não considerarmos o contexto, revela apenas versões aproximadas de sua existência.

A partir dessa visão a busca por uma unificação se torna inócua, ao invés disso temos outro desafio que é descobrir o referencial ao qual tal manifestação é funcional. Em outras palavras, se alguma situação causa incômodo sua resolução compreende desvendar a quem ou a o que tal incômodo é conveniente. Diante desta circunstância duas atitudes podem surgir; incorpora-se o incômodo ${ }^{[7]}$ e aceita-o pela incapacidade 
de alterar sua função, ou modifica-se a função descartando assim o evento como incômodo.

As coisas são o que são e estão onde estão porque para alguém ou algo é convenientemente funcional que assim sejam e estejam. Desta maneira a TCF prevê que podemos apenas refletir e compreender que os elementos constituintes da materialidade podem ser ou estar e que não há essência em ser ou estar.

Para ajudar na compreensão dessa proposta reúno algumas informações já aceitas pelo paradigma científico atual, direta ou por consequência, sob forma de postulados.

1 - A existência/realidade é função direta da observação. (Interpretação de Copenhague)

2 - A observação nunca é isenta de motivação (utilidade/função).

3 - De todas as possibilidades de arranjo em um grupo de elementos a mais funcional é a mais provável, esteja ele recebendo ou cedendo energia.

4 - A Forma é uma qualidade de partículas que agrega funcionalidade, tal qual a massa e carga elétrica.

Assim a propriedade massa ocorre quando a função de ser matéria (interações gravitacionais e inerciais) é mais conveniente. Por exemplo uma pessoa que deseja sentar busca ao seu redor uma cadeira. Se no ambiente houver alguma probabilidade de partículas formarem um sistema que tem por função ser uma cadeira, a qualidade massa daquelas partículas que constituem o sistema, se manifesta no campo de probabilidade local.

A carga elétrica também se manifesta quando as interações eletromagnéticas são mais convenientes, como exemplo, a repulsão elétrica entre as eletrosferas dos átomos da cadeira e da pessoa, já que a repulsão eletromagnética é cerca de $10^{40}$ vezes mais intensa que a atração gravitacional evita-se desta forma que a pessoa atravesse a cadeira possibilitando exercer a função de acondicionar alguém sentado. 
Proponho que tal qual a massa e a carga elétrica, o arranjo das partículas mediante sua função dentro do contexto é uma propriedade fundamental da matéria e como tal deve ser considerada como variável sistêmica que tem como premissa representar a relação entre observador e observado no sentido de sua disposição espaçotempora|[8], ou se preferirem de sua predisposição espaço-temporal.

Desta maneira, este arranjo, denominado por nós de Forma, possui as mesmas atribuições das grandezas físicas descritas como massa e carga, desde suas transmissões via campo até sua mediação como partícula.

\subsection{FORMA, UMA QUESTÃO ONTOLÓGICA}

De acordo com o contexto, forma pode ser empregada em diversas situações. Seu uso comum serve para demonstrar uma figura externa de um material sólido. É por isso que podemos classificar os diferentes objetos em quadrados, esferas, círculos, entre outros. Neste sentido, a classificação das formas se refere às formas geométricas. Por outro lado, o conceito de forma está relacionado à organização das coisas em nossa mente. A maneira como algo é estabelecido, ou então, o modo como é feito também é conhecido como forma.

Para Aristóteles, matéria e forma são princípios distintos, mas absolutamente complementares. A matéria se define por aquilo que uma coisa existe ou quando algo for feito, e representa a essência da substância. Por exemplo, se uma mesa foi feita de pedra, sendo esta sua principal substância, a pedra é, por natureza, o fundamento da essência; é a matéria. Por outro lado, a mesa, ao ser feita, adquiriu um determinado modelo; é justamente essa determinação que se entende por forma. Então, a forma faz com que uma coisa seja isso ou aquilo, e seu aspecto referencial, é meramente acidental e não substancial. Mas a que serve a natureza da mesa (pedra)? Sua funcionalidade (forma) parece ser mais útil pois, se pensarmos em apoiar pratos ou panelas, efetivamente não importa se a mesa é de pedra ou madeira. Entendo claramente que o conjunto de pés e tampo juntos é mais efetivo do que separados, uma vez que se estivessem simplesmente amontoados não teriam a forma de mesa e, portanto, sem função. No entanto, de acordo com a premissa, se de alguma maneira interagirmos com os mesmos, tornam-se potenciais de ser mesa(função) o que de maneira consciente passam a ser realidade. 
A forma parece mais sutil do que a essência. Tão sutil e imaterial a ponto de não ser sensível aos sentidos. Ela surge em nossa mente e não requer nada material exceto uma experiência anterior daquilo que supostamente, como no exemplo, chamamos de mesa. Sendo assim, sobre sua propagação, já que não arrasta matéria pode ser transmitida como onda tal qual a luz. Mas a luz em sua propagação é uma interação de campos elétrico e magnético então talvez a forma também possa se propagar da mesma maneira. Um campo que transporta a forma, que dá origem a ela quando as partículas que são por ele sensibilizadas se encontram em seu interior, um campo MORFO (forma) GENETICO (radical indo-europeu «nascer, gerar»), um campo que gera a forma.

Como na proposta coloco a forma como uma qualidade da partícula tal qual a massa e a carga elétrica e ainda lembrando que essas qualidades se propagam através de seus respectivos campos, recorremos ao trabalho do biólogo Rupert Sheldrake ${ }^{[9]}$ sobre campos morfogenéticos. Segundo ele:

Os campos morfogenéticos podem ser considerados análogos aos campos conhecidos na física no sentido de que são capazes de organizar mudanças física, embora não possam ser observados diretamente. O campo gravitacional e eletromagnético são estruturas espaciais invisíveis, intangíveis, inaudíveis, insípidas e inodoras; só são detectáveis graças a seus respectivos efeitos, gravitacional e eletromagnético. Para justificar o fato de que os sistemas físicos se influenciam mutuamente à distância e sem qualquer conexão material aparentemente entre eles, estes campos hipotéticos são dotados da propriedade de atravessar o espaço vazio ou mesmo constitui-lo. Em certo sentido são não materiais; mas em outro sentido, são aspectos da matéria, pois são reconhecidos graças a seus efeitos sobre sistemas materiais. Do mesmo modo, os campos morfogenéticos são estruturas especiais detectáveis apenas por meio de seus efeitos morfogenéticos sobre sistemas materiais; eles também podem ser considerados aspectos da matéria se a definição de matéria for ampliada ainda mais para incluí-los. (SHELDRAKE, 2013, p 94).

Reconheço a contribuição de Sheldrake sobre os campos morfogenéticos(mórficos), bem como sua sugestão de ampliar o conceito de matéria considerando os mesmos como campos físicos. Neste sentido acredito que o tratamento dos campos mórficos deverá seguir os mesmos moldes dos campos gravitacional e elétrico, desde que a RC: 34820

Disponível em: https://www.nucleodoconhecimento.com.br/fisica/conveniencia-funcional 
forma seja considerada uma propriedade da matéria tal qual a massa ou a carga elétrica. Se cada qualidade da partícula desenvolve seu próprio campo, a forma não deve ser diferente.

A analogia dos campos morfogenéticos com os campos físicos está em sua existência/comprovação uma vez que o campo gravitacional só é observável em seus efeitos sobre partículas dotadas de massa, assim como o campo eletromagnético só é comprovado por seu efeito sobre cargas elétricas, propomos que o campo morfogenético tenha seu efeito observado sobre a forma das partículas. Se a mudança no comportamento de partículas dotadas de carga e/ou massa quando imersas em seus respectivos campos ratifica a existência desses campos, a modificação na forma ou organização das mesmas também comprovaria a existência dos campos morfogenéticos.

De acordo com nosso quarto postulado ${ }^{[10]}$ o conceito de campo morfogenético, bem como sua comprovação, fica atrelado à causa da forma dos sistemas, e sua influência tem por si só maior ou menor intensidade de acordo com a necessidade e/ou importância que a organização da partícula/sistema tem em relação ao contexto.

Entendemos também que o aspecto final de um agrupamento pode ser representado em função de sua estabilidade mecânica funcional (massa), estabilidade eletromagnética (carga elétrica) ou ainda estabilidade organizacional (forma), dependendo na necessidade de subsistência do sistema em sua conexão com o ambiente.

Essa necessidade natural dos sistemas em se acomodar diante das variações do ambiente é mais bem compreendida se lançarmos mão do conceito de autoorganização.

\subsection{ORGANIZAÇÃO E AUTO-ORGANIZAÇÃO}

Organização, do grego organon, é uma palavra relacionada a agrupamentos que, tendo elementos (composição) juntos (conectividade) se constroem (estrutura) formando núcleos/ subsistemas (Integralidade) que permitem, desta maneira, o surgimento de funções/propriedades singulares ao conjunto (Funcionalidade). 
Graças à organização um sistema assume propriedades que não podem ser encontradas nas entidades isoladas, ou mesmo na simples reunião delas. Quando um elemento externo ao sistema provoca a reunião das partes entendemos que o evento ocorre a custas de um fornecimento de energia e desta maneira temos uma organização forçada, cuja manutenção remete à instabilidade (vide figura 1).

A probabilidade das bolas se organizarem em uma pilha é muito pequena, sugerindo então que alguém (elemento externo) faça isso, ou seja, alguém forneceu energia para que o sistema se organizasse daquela maneira. Observemos ainda que o conjunto possui uma energia potencial devido à sua organização. No entanto quando um sistema é sujeito a um estímulo mínimo externo (alguém tira uma bola da base), este se acomoda de maneira mais estável (vide figura 2), o que é comum estar associado a uma desorganização que indica um grau mais alto de entropia.

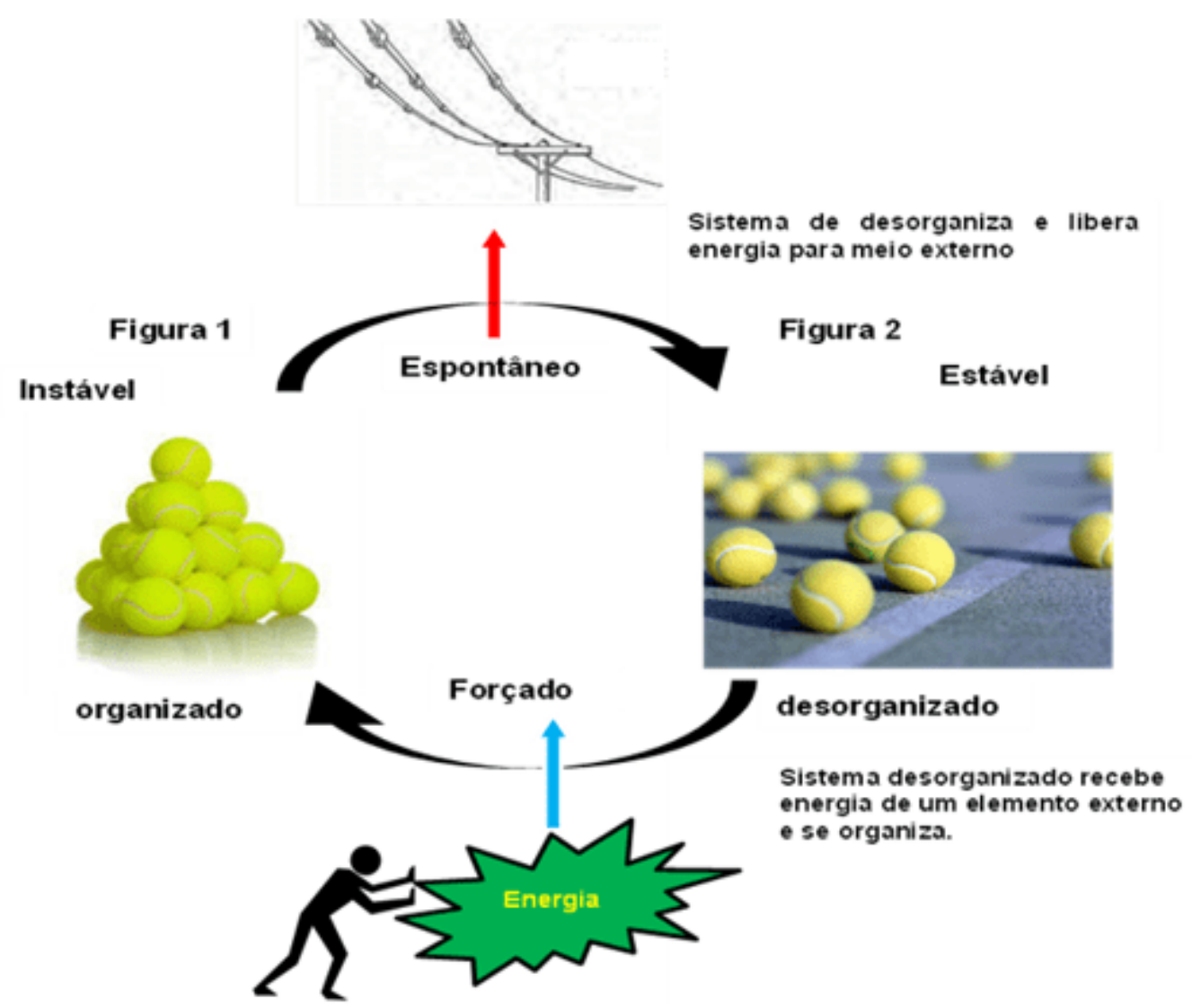

Fonte: Elaborada pelo autor.

Para que isso ocorra, o sistema libera energia ao meio externo( como uma queda d'água) e é nesse contexto que o ser humano demonstra sua maior habilidade que é RC: 34820

Disponível em: https://www.nucleodoconhecimento.com.br/fisica/conveniencia-funcional 
reconhecer as transformações de energia e utilizá-las em seu benefício, pois compreende que ao observar a tendência dos sistemas à desorganização, pode usufruir da energia liberada a seu favor.

A maneira como o sistema se estabiliza parece desorganizado, no entanto, se prestarmos um pouco mais de atenção, perceberemos que de todas as possibilidades de desorganização uma em especial foi escolhida. É como se os integrantes do sistema produzissem o resultado final, de acordo com a necessidade de adaptação ao ambiente, para atingir sua estabilidade.

Nesse contexto, entendo que a desorganização de um sistema é o resultado de um processo de auto-organização, ou seja, um evento espontâneo, não aleatório e com a característica de que a repetição aumenta sua recorrência.

Um sistema para ser auto-organizado tem algumas características específicas, que definem para nós as condições fundamentais para o surgimento das propriedades físicas da matéria. São elas:

- Redundância Estrutural: É a repetição muito grande dos elementos básicos constituintes.

- Redundância Funcional: Semelhança entre os processos executados.

- Adaptação Funcional: Capacidade do sistema de deslocar e distribuir funções.

- Confiabilidade Sistemática: Quando sistemas altamente complexos possuem as 3

primeiras características eles adquirem a capacidade de aceitar um certo nível de intromissão(ruído/desordem) em sua organização sem que a estrutura entre em colapso.

$\mathrm{Na}$ verdade, o sistema utiliza esse fator de desequilíbrio como elemento de complexificação para que se auto organize em um nível superior de estabilidade. A TCF relaciona essa tendência ao conceito de evolução.

Um sistema ao evoluir incorpora outros subsistemas causadores de tais interferências ampliando sua rede e de certa maneira garante sua existência. Somente pela autoorganização é possível promover essa independência pois uma organização exige de RC: 34820

Disponível em: https://www.nucleodoconhecimento.com.br/fisica/conveniencia-funcional 
um elemento externo sempre uma certa quantidade de energia para manter seu status de detentor da ordem.

Como mencionado anteriormente, uma forma é dita auto-organizada quando se produz a si própria, o que significa apresentar a capacidade de criar padrões de comportamentos não previsíveis, descentralizados e em alguns casos, de crescente adaptação. Uma vez auto-organizado, sistemas semelhantes terão mais chances de repetir a mesma configuração, o que explicaria a memória integrada nos campos mórficos no trabalho de Sheldrake (2013) quando ele cita a cristalização espontânea de substâncias. O Ritonavir (droga usada no tratamento da AIDS), produzida pelo Laboratório Abbot, estava no mercado há 18 meses quando, na sua produção, começou a aparecer outro polimorfo desconhecido até então. Embora tivessem a mesma fórmula, suas diferenças estruturais mostravam dificuldades de solubilidade. Após o aparecimento desse novo polimorfo, o composto original nunca mais pôde ser produzido isoladamente, obrigando a empresa retirar o medicamento do mercado.

A competição entre as formas pode ser explicada pela estabilidade termodinâmica; no entanto, a transmissão dessa informação fica a critério da ressonância mórfica[11], pois antes do surgimento das novas formas não havia competição, e depois que sugiram, apareceram nos laboratórios do mundo todo inviabilizando a retomada do composto original.

O computador é um exemplo de organização pois realiza com velocidades incríveis as instruções dos usuários seguindo um programa pré-definido. A analogia com o cérebro humano é no mínimo equivocada, já que este último transcende o conceito de pré-programação, se auto organizando, conduzindo e conectando as informações aferidas do ambiente externo pelos cinco sentidos com as informações armazenadas na memória. Uma característica desta rede neuronal é sua enorme plasticidade, em que há constante formação de novas conexões e destruição de antigas. A autoorganização no sistema neural permite ao homem desenvolver sua cognição e criatividade.

Outros exemplos de comparação entre sistemas organizados e auto organizados mais tangíveis à nossa experiência cotidiana são os semáforos e rotatórias. Um conjunto 
de semáforos (organizado) regula o trânsito em um cruzamento "de fora" (externo ao sistema).

Já as rotatórias (auto organizado) leva aos motoristas uma maior responsabilidade, pois a decisão de "passar / esperar" é transferida para estes (internos ao sistema). Orientar-se-ão por algumas regras simples internas que irão determinar quando é permitido entrar na rotatória.

Para que ocorra a manutenção do sistema a auto-organização acaba por determinar qual ou quais propriedades sistêmicas serão mais apropriadas à manifestação. Em alguns casos não são os estados de menor energia as melhores opções, por vezes a necessidade da forma supera a estabilidade energética.

Um exemplo disso é a água, cuja molécula possui geometria angular porque o átomo central (oxigênio) tem dois pares de elétrons não ligantes.

De acordo com o conceito de estabilidade, a conformação de menor energia estrutural deveria ser a linear, uma vez que seria possível a distribuição dos dois pares de elétrons em uma conformação espacial tridimensional simétrica, ou seja, o formato linear satisfaria a repulsão elétrica e a estabilidade estrutural visto que o momento angular seria nulo (sistema isolado). No entanto, a água, na forma linear, seria considerada apolar, sendo classificada como um gás nas CNTP ${ }^{[12]}$. A substância não faria ligação de hidrogênio, não se associaria e toda vida que conhecemos hoje não existiria, uma vez que a mesma, supostamente, surgiu na água em seu estado líquido.

Entendo que a Teoria da repulsão dos pares de elétrons da camada de valência explica de maneira cabal a geometria da molécula, mas isso é a explicação partindo da pré-existência das qualidades massa e carga elétrica de seus constituintes. O que estou propondo é que a conveniência funcional desta geometria é anterior à manifestação de tais propriedades. A forma (a auto-organização) se torna mais importante que a configuração de mínima energia.

Ressalto ainda que a persistência na formação de moléculas de água é mais um exemplo de repetição de padrões formativos que Sheldrake chama de ressonância mórfica e continua ocorrendo para sustentar a vida, função maior do sistema. Se ampliarmos nossa atenção e se pudermos romper com o paradigma que mantém a RC: 34820

Disponível em: https://www.nucleodoconhecimento.com.br/fisica/conveniencia-funcional 
molécula de água como angular e ainda, só por um momento, considerarmos a possibilidade de uma nova geometria, perceberemos que a forma da mesma não é inerente a ela, mas resultado das infinitas vezes que o evento ocorreu e por isso tem muito mais possibilidade de continuar ocorrendo.

Essa recorrência faz com que interpretemos de forma ilusória que a molécula de água seja estável e natural, acreditando como consequência que ela existe independente de nós. Insistimos em dizer que ela só é assim porque é conveniente ao sistema que assim seja e que nossa interação a faz real.

A todo momento átomos surgem, elétrons preenchem as mesmas órbitas ao redor do núcleo; átomos se combinam repetidamente para produzir as mesmas formas moleculares. Essa repetição pode ser explicada não por que existem leis físicas imutáveis que determinam formas eternas, mas por conta de uma influência de causa formativa anterior, ou seja, o campo morfogenético de sistemas passados aumenta a possibilidade de formas futuras se manifestarem.

\section{CONSIDERAÇÕES FINAIS}

Como vimos, as qualidades da matéria dependem do seu estado peculiar de associação e manifestam-se naquilo que for mais funcional e, portanto, mais conveniente ao sistema. Desta maneira proponho que a funcionalidade seja a causa do arranjo espaço-temporal (forma) de um sistema de partículas e que a predisposição deste arranjo seja também considerada uma propriedade das partículas tal qual a massa, carga elétrica, cor, sabor.

$\mathrm{Na}$ verdade, intuo que estas propriedades sejam recursos que a partícula desenvolve para se associar e assim sendo não são próprias da partícula, mas resultado de suas conexões.

Tais propriedades são determinadas por suas relações entre si e com o meio, de acordo com a conveniência e ratificadas pela observação. Sob essa perspectiva, todas as qualidades da matéria são criadas mediante a necessidade de se autoorganizar em um arranjo funcional no contexto do sistema no qual observador e observado integram o que chamamos de realidade. A única propriedade fundamental 
do universo é a associação, o arranjo, a auto-organização, que neste ensaio denomino de forma.

O desdobramento dessa pesquisa pode contribuir com a Teoria do Campo Unificado, uma vez que tenho a convicção de que a causação formativa (campo mórfico) parece se antecipar a todas as propriedades da matéria, desmistificando a inerência das mesmas e vinculando-as a conveniência funcional. Daí o nome de Teoria da Conveniência Funcional.

Uma das consequências desta teoria é o fato de que se todas as propriedades ditas fundamentais até agora sejam resultado da conveniência funcional, o tempo seria a única medida verdadeiramente inerente à realidade.

Dentro do pressuposto deste universo centrado na relação observador e observado acredito que uma possível quantização do tempo seja o gradiente de complexidade cedido ou adquirido pelo sistema na tentativa de se auto-organizar. O grau de complexidade estrutural seria proporcional a capacidade do sistema absorver ruídos(interferências) e ainda manter sua integridade funcional. Deverá existir um valor mínimo deste gradiente de complexidade independente da manifestação de quaisquer propriedades. Como cada sistema pode se relacionar com outro sistema e assim alterar seus gradientes de complexidade, a medida mínima deverá ocorrer na impossibilidade de relação, o que significa imaginarmos todos os sistemas em um único grande sistema.

O tempo nesta configuração perderia seu significado, ou seja, os eventos em eterno presente. Imaginemos como seria o estágio da evolução humana se conseguíssemos compreender o universo como um único sistema e nos relacionarmos a partir dele. Nos livrar da obsessão do tempo atentando somente a uma única oportunidade e que por ser única torna-se tão especial por também entender que o viés de nossa materialidade está acondicionado em um eterno nascer e morrer a todo instante, existir e não existir em todo momento.

Resta então o desafio proposto anteriormente, para quem ou o que o Universo deverá ser funcional? 
De acordo com a TCF, é funcional a quem o compõe, ou seja, a nós mesmos, o que nos coloca em uma condição um pouco desconfortável pois atribui somente a nós a responsabilidade de manter o Universo existindo. Como ainda não temos meios de inferir tal proposição, talvez possamos apenas considerar a hipótese.

No âmbito das relações sociais parto da premissa de que o ser humano tem a tendência a se agrupar, se associar. Essa tendência provavelmente tem origem na intuição de que ao formar grupos teremos maior chance de sobreviver às influências externas. Desta forma quando compartilhamos de uma mesma realidade temos a possibilidade de nos conectar a partir dela, ou seja, temos algo em comum que nos motiva a formar um grupo (um sistema). Quanto mais pontos em comum tivermos, mais forte nossas conexões.

Vamos voltar ao exemplo da cadeira onde a conveniência de um observador em encontrar um objeto que tenha a função de acomodá-lo sentado faz com que se manifeste massa e carga elétrica nas partículas que podem, a partir do seu campo, produzir a materialização de uma cadeira. Outro indivíduo pode percebê-la também, talvez não para sentar-se, mas para compartilhar da mesma conveniência criando uma experiência em comum e consequentemente a possibilidade de associação. Isso seria uma explicação bastante simples sobre o motivo de indivíduos diferentes produzirem a mesma realidade. Isso ocorre porque o objeto em si não é o elemento mais importante, mas sim a conveniência de que o mesmo seja real aos que observam. É a associação gerada pelo compartilhamento desta manifestação que os mantêm em conexão garantindo aos integrantes uma funcionalidade que é a razão de sua existência.

Entendo que a materialidade não é algo intrínseco, mas resultado da necessidade de associação. Desta maneira tal qual um arranjo molecular, todo sistema social é pautado nessa concepção, uma vez que criamos grupos porque comungamos de uma mesma conveniência. A existência de um evento comum é sustentada pela necessidade de manter o grupo. A crença compartilhada de que algo exista fornece uma qualidade que sustenta o sistema, não pela existência do objeto ou evento propriamente dito, mas pelo agrupamento motivado por esta crença. 
A partir deste momento, para manter a associação, cada elemento toma para si uma função baseada em sua própria conveniência e constrói sua própria concepção de universo. A manutenção das conexões garante sua importância diante do sistema por ele criado. É por isso que o indivíduo desenvolve seus valores e prerrogativas sempre na tentativa de sustentar seu mundo. Esta atitude é uma maneira de garantir o controle das interações que ele mantém com o sistema.

Estar consciente de sua função frente a uma determinada organização é o maior desafio do indivíduo. Um mesmo indivíduo pode participar de sistemas diferentes com funções diferentes, por exemplo, no trabalho ele pode ser um técnico em informática, em casa ser pai, na escola ser professor ou estudante.

Não há uma essência única, mas uma habilidade singular de modular funções, no entanto, esta habilidade passa despercebida pela maioria das pessoas que acreditam ter uma só face, uma base primordial só que na verdade temos múltiplas faces. Ao assumir que possuímos uma essência rejeitamos o exercício de modularmos nossas funções em prol de uma busca quixotesca de nosso bloco fundamental tal qual a ciência o fez sem sucesso. Essa postura de dizer que nossa essência permite ou não tal coisa é uma maneira de terceirizar nossa responsabilidade diante das nossas relações.

A manutenção destas relações exige adaptações funcionais pois caso um dos integrantes não consiga mais executar dada função, outros poderão exercê-la (plasticidade). Para responder a um certo nível de interferência o sistema entra em um movimento auto-organizativo onde é necessário, por vezes, uma adaptação na execução de tarefas, o que chamamos anteriormente de redundância funcional.

A partir desta necessidade sistêmica os integrantes têm duas possibilidades, promover conscientemente esta modulação funcional e o conjunto evolui ou, insistir em manter a mesma função, o que significa buscar outro sistema para exercê-la.

A insistência de um elemento em manter a mesma função é causada pela estabilidade energética e sendo assim, desprovidos desta reflexão, indivíduos que não desenvolvem essa habilidade preferem mudar de ambiente a modular suas funções. As vezes essa falta de percepção é tamanha que o indivíduo não se encaixa em 
nenhum outro sistema, perdendo efetivamente sua função e consequentemente sua importância e razão de existir.

A teoria vem mostrar que como qualquer conjunto de elementos, nós como seres sociais fazemos essas adaptações a todo momento. A crença em uma única função é o que determina o individualismo e atribui ao elemento uma importância intrínseca, que ele verdadeiramente não tem, exatamente da mesma maneira que atribuímos qualidades intrínsecas à matéria.

$\mathrm{Na}$ verdade, quando uma ou mais qualidades se manifestam, naquele lapso temporal elas são únicas. Isto faz com que acreditemos que sejam inerentes, mas só o são diante da necessidade daquele instante. A análise desta falsa importância foge ao escopo deste ensaio, no entanto, parece que a individuação vai de encontro à necessidade de subsistência.

Como é um trabalho em construção reconheço as lacunas conceituais e a ausência do formalismo matemático, embora as tentativas sejam promissoras. Reforço aqui o desejo de que esse ensaio seja uma maneira de agregar outros pesquisadores, que comunguem de perspectivas correlatas e que consigamos trabalhar juntos nesta direção.

A existência está no funcional e a realidade encontra-se na conveniência.

\section{REFERÊNCIAS}

ARISTOTELES, Metafísica vols. I, II, III, 2ª edição. Ensaio introdutório, tradução do texto grego, sumário e comentários de Giovanni Reale. Tradução Portuguesa Marcelo Perine. São Paulo. Edições Loyola. 2002.

CHALMERS, D.J. (1995) 'Facing Up To The Problem Of Consciousness', Journal of Consciouness Studies,2, No. 3, pp 200-19.

DAMÁSIO, ANTÓNIO R. (2000). O mistério da consciência. São Paulo: Companhia das Letras. 
DEBRUN, M. Auto-organização: estudos interdisciplinares. Campinas: UNICAMP, Centro de Lógica, Epistemologia e História da Ciência, 1996. (Coleção CLE, v.18)

KELLY, G.A. A Theory of personality - The psicology of personal constructs. New York. W.W. Norton \& Company, 1963.189p.

NUSSENZVEIG, H. M. Curso de Física básica: 3 Eletromagnetismo. São Paulo: Edgard Blucher, 2001.

PRIGOGINE, I. \& GLANSDORFF, P. Structure, stabilité et fluctuations. Paris: Masson, 1971.

ROVELLI, Carlo. A realidade não é o que parece: A estrutura elementar das coisas. 1 Ed, Rio de Janeiro: Objetiva, 2017.

SHELDRAKE, RUPERT, Uma nova ciência da vida: A hipótese da causação formativa - São Paulo, Ed. Cultrix, 2013.

STONIER, T., (1990) Information and the Internal Structure of the Universe. An Exploration into Information Physics. Springer Verlag, New York.

WHEELER, J. (1990) 'Information, Physics, Quantum: The Search for Links', in Complexity, Entropy, and the Physics of Information, edited by Wojciech H. Zurek, Addison-Wesley.

YOUNG, H. D.; FREEDMAN, R. A. Sears e Zemansky Física III: Eletromagnetismo. Tradução e revisão técnica de Adir Moysés Luiz. 10. ed. São Paulo: Addison Wesley, 2004.

2. Neste momento do trabalho o termo é abordado em sua definição clássica embora a Física já algum tempo tenha minimizado sua preocupação com a busca dos blocos fundamentais, se atentando mais aos fenômenos do que com as coisas, penso ser mais adequado fundamentar a teoria priorizando a realidade dentro do contexto dos objetos macroscópicos do cotidiano e não extrapolando-os ao universo quântico onde a modelagem matemática torna-se fundamental para sua manifestação, fugindo do escopo inicial deste ensaio. 
3. Outras partículas foram sendo detectadas, dentre elas a partícula de Hideki Yukawa (1907-1981), chamada de píon, em 1947, através de estudos de chuveiros atmosféricos gerados por raios cósmicos. Entre 1950 e 1960 surgiram aceleradores de partículas que permitiram que reações muito mais energéticas fossem realizadas. Uma nova propriedade das partículas foi descoberta, a estranheza, que é uma característica intrínseca da partícula, como a sua massa e sua carga elétrica. (Rev. Bras. Ensino Fís. vol.29 no.2 São Paulo 2007).

4. Há quatro tipos de interações fundamentais: eletromagnética, gravitacional, forte e fraca. A interação entre um elétron e um núcleo atômico (eletromagnética); a atração entre quarks é do tipo interação forte; o decaimento $\beta$ exemplifica a interação fraca; a interação gravitacional atua entre todas as partículas massivas, e é a que governa o movimento dos corpos celestes.

5. Desenvolvida por Niels Bohr e Werner Heisenberg que trabalhavam juntos em Copenhague em 1927. Considera sem sentido perguntas como "onde estava a partícula antes de a sua posição ter sido medida? Ela defende que em Mecânica Quântica, os resultados são indeterminísticos e que o ato de observar provoca o "colapso da função de onda.

6. Ph.D. em física quântica, autor de inúmeros artigos científicos, além de professor titular de física no Instituto de Física Teórica da Universidade do Oregon.

7. Busco associar a palavra incômodo ao conceito de ruído presente na teoria de redes complexas onde é possível observar a distinção entre o símbolo (objeto da codificação), o sinal (que é o suporte físico) e o ruído (que é a perturbação da informação).

8. Sistema de coordenadas utilizado como base para o estudo da relatividade restrita e relatividade geral. O tempo e o espaço tridimensional são concebidos, em conjunto, como uma única variedade de quatro dimensões a que se dá o nome de espaçotempo. Um ponto, no espaço-tempo, pode ser designado como um "acontecimento". Cada acontecimento tem quatro coordenadas ( $t, x, y, z)$; ou, em coordenadas angulares, $t, r, \theta$, e $\varphi$ que dizem o local e a hora em que ele ocorreu, ocorre ou ocorrerá. 
9. Biólogo, bioquímico, parapsicólogo, escritor e palestrante inglês; mais conhecido por sua teoria da morfogênese. Pesquisador em bioquímica e fisiologia vegetal, descobriu junto com Philip Rubery, o mecanismo de transporte da auxina.

10. A forma é uma qualidade dos sistemas que agrega funcionalidade tal qual a massa e carga elétrica.

11. O conhecimento adquirido por um conjunto de indivíduos agrega-se ao patrimônio coletivo, provocando um acréscimo de consciência que passa a ser compartilhado por toda a espécie. E esse processo de coletivização da informação foi denominado por Sheldrake de "ressonância mórfica". É através dela que as informações se propagam no interior do campo mórfico, alimentando uma espécie de memória coletiva.

12. Condições Normais de Temperatura e Pressão

Enviado: Fevereiro, 2019.

Aprovado: Julho, 2019. 